\title{
Tradição alimentar: elemento de emancipação frente a mecanismos globais de dominação
}

\author{
Food tradition: emancipation element front of \\ Mechanisms of domination global
}

\author{
Ana Claudia Guske \\ Universidade de Santa Cruz do Sul - UNISC - Santa Cruz do Sul - Rio Grande do Sul - Brasil

\section{Erica Karnopp} \\ Universidade de Santa Cruz do Sul - UNISC - Santa Cruz do Sul - Rio Grande do Sul - Brasil
}

Resumo: No contexto do modo de produção capitalista, mecanismos globais de dominação acarretam a homogeneização e padronização dos diferentes espaços. Este estudo possui o objetivo de apresentar o espaço rural e as tensões que nele se fazem presente. A Microrregião Norte do Conselho Regional de Desenvolvimento do Vale do Rio Pardo é o recorte espacial adotado que se caracteriza amplamente pela produção de commodities, porém conta com um número significativo de agroindústrias familiares de alimentos. A tradição alimentar manifestada nos produtos provenientes das agroindústrias familiares expressa a identidade territorial. Assim, a preservação da tradição alimentar, através das agroindústrias familiares se torna um elemento de emancipação frente a mecanismos globais de dominação.

Palavras-chave: Tradição. Alimento. Agroindústria familiar.

\begin{abstract}
In the context of the capitalist mode of production, global domination mechanisms lead to the homogenization and standardization of different spaces. This study has the objective of presenting the countryside and stresses that it is doing this. The northern microregion of Rio Pardo Valley Regional Development Council is adopted spatial area that is characterized largely by the production of commodities, but has a significant number of family agribusiness food. The food tradition manifested in the products from family farms expresses the territorial identity. Thus, the preservation of food traditions through family agribusinesses becomes a front emancipation element to global domination mechanisms.
\end{abstract}

Keywords: Tradition. Food. Family agribusiness. 


\section{Introdução}

O atual cenário da questão agrária brasileira, baseado no modelo agrícola neoliberal, se desenvolve, por um lado, segundo os interesses de atores externos, ou seja, de fora das próprias regiões. Nesse caso, as sociedades regionais e a organização espacial estão submetidas a profundas transformações. Por outro lado, observa-se a expansão de atividades em parte não incorporadas aos circuitos econômicos globalizados, assim como a persistência de formas de sobrevivência, também baseados em circuitos regionais.

Os conflitos e os tensionamentos de interesses estão presentes no contexto do meio rural. A divergência mais contundente envolve a agricultura familiar e a agricultura patronal. O primeiro visa à posse da terra e o trabalho com participação do grupo familiar; o segundo, com o auxílio de alta tecnologia e produtividade, busca o lucro através das regras impostas por atores globais.

Este artigo tem como objetivo analisar a tradição alimentar como elemento de emancipação de agricultores familiares frente a mecanismos globais de dominação. A Microrregião Norte do Conselho Regional de Desenvolvimento - COREDE do Vale do Rio Pardo/RS, a partir das experiências na produção de alimentos por meio de agroindústrias familiares, será o objeto empírico de análise.

Mas o que é a tradição? A tradição envolve de alguma forma, controle do tempo. "A tradição é uma orientação para o passado, de tal forma que 0 passado tem uma pesada influência ou, mais precisamente, é constituído para ter uma pesada influência para o presente". (GIDDENS, 1997: 80) A Tradição integra e monitora a ação à organização tempo-espacial da comunidade (ela é parte do passado, presente e futuro; é um elemento intrínseco e inseparável da comunidade). Ela está vinculada à compreensão do mundo fundada na superstição, religião e nos costumes; ela pressupõe uma atitude de resignação diante do destino, o qual, em última instância, não depende da intervenção humana, do "fazer a história". Dessa forma, conhecer é ter habilidade para produzir algo e está ligado à técnica e à reprodução das condições do viver. A ordem social sedimentada na tradição expressa a valorização da cultura, do passado e dos símbolos enquanto fatores que perpetuam a experiência das gerações.

Por outro lado, a tradição também se vincula ao futuro. Mas este não é concebido como algo distante e separado, mas como uma espécie de linha contínua que envolve o passado e o presente. É a tradição que persiste, remodelada e reinventada a cada geração. Não há um corte profundo, ruptura ou descontinuidade absoluta entre o ontem, hoje e o amanhã.

A tradição envolve o ritual; este constitui um meio prático de preservação. Nas sociedades que integram a tradição, os rituais são mecanismos de preservar a memória coletiva e as verdades inerentes ao tradicional. O ritual reforça a experiência cotidiana e refaz a liga que une a comunidade, mas ele tem uma esfera e linguagem próprias e uma verdade em si, isto é, uma "verdade formular" que não depende das "propriedades referenciais da linguagem". Pelo contrário, "a linguagem ritual é performativa, e às vezes pode conter palavras ou práticas que os falantes ou os ouvintes mal conseguem compreender. (...) A fala ritual é aquela da qual não faz sentido discordar nem contradizer - e por isso contém um meio poderoso de redução da possibilidade de dissenção". (Id.: 83)

De algum modo, a intensificação de processos de transformação em vários âmbitos da realidade social provoca a emergência, com bastante força, do conceito de tradição, como se fosse um contraponto a estes acontecimentos. Somos provocados, assim, a refletir sobre os contrastes inerentes à realidade social, neste caso - no contexto das agroindústrias familiares.

Portanto, os alimentos tradicionais, também são produtos com história, pois se constituem e fazem parte de um local e de uma determinada cultura, sendo produzidos com a matéria-prima local de uma determinada região. Devido aos conhecimentos e saberes-fazeres presentes nesses alimentos, através de gerações, a sua produção 
resgata não só a história envolta neles, mas o caráter histórico do próprio agricultor. Os produtos tradicionais, também são denominados produtos com história, pois se constituem e fazem parte da história social de uma determinada cultura. Vindos de um longo tempo, através de gerações que os foram produzindo e recriando, esses produtos marcam um processo que reúne relações sociais e familiares, num encontro entre o saber e a experiência; portanto, a produção desses alimentos é, ainda, uma arte construída ao longo do tempo através da tradição familiar (RIBEIRO e MARTINS, 1995).

\section{O TERRITÓRIO RURAL: ASPECTOS RELEVANTES}

Segundo Santos (2000), a racionalidade hegemônica global se apresenta como uma ideologia comandada pelos atores hegemônicos do capitalismo, sobretudo as macroempresas. Essa racionalidade é transmitida para a sociedade através das verticalidades, que se espacializam no território como um conjunto de pontos formando um espaço de fluxos, e que estão profundamente adequados às tarefas produtivas hegemônicas. Nas verticalidades predomina o tempo rápido/universal, e os interesses corporativos sobressaem-se sobre os interesses públicos.

O sistema de produção que se serve das verticalidades é constituído por redes, estas a serviço daqueles atores que, de fora da área, determinam as modalidades internas de ação nos lugares, organizando o trabalho de todos os outros atores. As decisões essenciais, concernentes aos processos locais são estranhas ao lugar e obedecem a motivações distantes, tendo como consequência a alienação das pessoas presentes nos lugares (Santos, 2000).

Para Santos (1999), a dimensão horizontal corresponde às atividades e ações que possibilitam a estruturação da vida social: os lugares podem se unir horizontalmente, reconstruindo aquela base de vida comum, suscetível de criar normas locais, normas regionais que acabam por afetar as normas nacionais e globais. Justamente, as redes de solidariedade fomentam a coesão social como resposta a marginalização e exclusão, alternativa às políticas setoriais e ao processo de globalização que muitas vezes não atendem aos interesses de desenvolvimento articulado de determinado território ou região.

Sob essa perspectiva, a dialética no/do território se afirma mediante um controle local da parcela técnica da produção e um controle remoto (global) da parcela política da produção. Assim, há um conflito que se agrava entre um espaço local e um espaço global, este último com um conteúdo ideológico de origem distante, que chega a todos os lugares (SANTOS, 2002).

O território precisa ser interpretado - e não apenas considerado como uma variável de descrição das diferenças na repartição econômica. A interrogação mais forte acerca do território é a que procura compreender a genealogia dos processos socioeconômicos: por que razão se gera ali, e não noutro sítio, dinâmicas ou déficits? Isto implica uma epistemologia do território. Rejeita-se a visão organicista que vê os territórios como derivações, subprodutos, de ordem imanente e se entende que se deve olhar para as sociedades (REIS, 2005).

Somente a partir dos anos 1970 é que se estruturou um pensamento alternativo a esta corrente hegemônica. A concepção teórica e metodológica que preside todas as formulações não conservadoras, a partir daí, é a de que o território é uma produção social, procurando analisar os conflitos que se estruturam e das lutas que se travam em torno deste ambiente construído socialmente. Nenhum recorte espacial poderá ser mais visto como passivo ou mero receptáculo e sem contexto institucional e moldura histórica.

É, portanto, analisando a nova realidade engendrada por obra do processo de globalização, vista por Santos (2002, p. 16) como "um resultado da nova construção do espaço e do novo funcionamento do território", que ele propõe dois novos recortes analíticos do território: verticalidades e horizontalidades. 
Para Santos (1999, p. 227), as verticalidades são "vetores de uma racionalidade superior e do discurso pragmático dos setores hegemônicos, criando um cotidiano obediente e disciplinado", segundo uma ordem que impõem para o seu próprio proveito. O mesmo autor associa as relações verticais com as chamadas forças centrífugas, que tendem a se afastar do centro (território em que se instalam), no sentido de que somente ali permanecem enquanto puderem extrair vantagens não alcançadas em outros territórios. Por essas razões, elas são consideradas como movimentos geradores de desagregação e fatores de divergência, tendendo a engendrar processos de verticalização.

Segundo Santos (1999, p. 227), “as horizontalidades são tanto o lugar da finalidade imposta de fora, de longe e de cima, quanto o da contrafinalidade, localmente gerada. Elas são o teatro de um cotidiano conforme, mas não obrigatoriamente conformista e, simultaneamente, o lugar da cegueira e da descoberta, da complacência e da revolta". Se as relações verticais se associam às forças centrífugas, as relações horizontais se associam às forças centrípetas, pois tendem ao centro (ao próprio território) e, por isso, se constituem como movimentos de agregação e fatores de convergência e de solidariedade, tendendo a engendrar processos de horizontalização.

Segundo Abramovay (1992), o dinamismo técnico, a capacidade de inovação e a completa integração aos mercados são características importantes para a definição de agricultura familiar. Ainda segundo o autor, nos países desenvolvidos, onde o capitalismo teria atingido um grau de desenvolvimento superior ao dos países subdesenvolvidos, o próprio sistema aniquilaria 0 campesinato e teria como principal base social de desenvolvimento 0 agricultor familiar. A "metamorfose" de camponeses em agricultores familiares ocorreria no interior deste capitalismo com um grau superior de desenvolvimento e com forte intervenção do Estado na estruturação dos mercados nacionais. Abramovay demonstra a importância da produção agropecuária com base no trabalho familiar nos Estados Unidos e no oeste europeu. O autor reconhece o papel indispensável que o Estado desempenhou nos países desenvolvidos para que os agricultores familiares atingissem tal capacidade produtiva. Não é o mercado o elemento decisivo para este desempenho, mas sim o Estado: o mercado está longe de ser o fator decisivo de alocação dos recursos produtivos na sociedade.

Cabe ressaltar que deveria também competir ao Estado, assim como nos países desenvolvidos, o papel de proteger os agricultores familiares através de subsídios para a garantia de competitividade ao atendimento das regras impostas pelo sistema capitalista.

Não é por acaso que Oliveira (1995) chama o agronegócio no Brasil de 'agronegocinho', ou seja, não há por parte do Estado um protecionismo fabricado, assim como ocorre nos países desenvolvidos. A agricultura familiar fica a mercê de sua integração absoluta ou não ao mercado agrícola. No caso do Brasil, o Estado não paga pelo desenvolvimento deste sistema na agricultura. A questão aqui colocada é que o Brasil, assim como a maioria dos países subdesenvolvidos, não adota medidas de contenção dos impactos do sistema capitalista na agricultura familiar.

O trabalho rural executado pelo grupo familiar, denominado de agricultura familiar, se contrapõe ao agronegócio ou à chamada agricultura na perspectiva empresarial. O agronegócio é desenvolvido nas grandes propriedades, com a incorporação de alta tecnologia, capaz de proporcionar aumento de produtividade. Apesar do aumento da produtividade, este ramo da agricultura nunca contribuiu para a redução da pobreza no meio rural. O agronegócio possui como característica a concentração de renda nas mãos de poucos e a não preocupação com a conservação dos recursos naturais.

Ramos (2001, p. 151) destaca que os pequenos e médios agricultores estão presentes em países desenvolvidos e são capazes de realizar uma exploração não predatória dos recursos naturais. 
O agronegócio é fruto da globalização, no sentido de que o setor se submete às regras ditadas por atores globais. A globalização no movimento de atravessar as fronteiras nacionais integra e conecta os processos a nível global. A internacionalização dos mercados e a integração da economia global modificam estruturas sociais em diferentes pontos do planeta.

No Brasil, a desvalorização da agricultura familiar e o estabelecimento de commodities fizeram com que a produção em larga escala, de determinadas mercadorias, fosse estimulada. As mercadorias, definidas pelo mercado internacional, como commodities não se preocupam em atender demandas regionais, pois atendem a critérios mundiais.

Em virtude dos processos de reestruturação capitalista e do aumento da vulnerabilidade social e econômica no meio rural, a diversificação produtiva tem se mostrado uma tendência na agricultura familiar. As ações de desenvolvimento local e/ou regional merecem destaque, sendo as agroindústrias familiares um exemplo concreto de estratégias de desenvolvimento em prol dos atores que as empreendem.

Neste sentido, se estabelece no espaço rural uma contraposição de interesses. A agricultura familiar, através da "exploração familiar corresponde a uma unidade de produção agrícola onde propriedade e trabalho estão intimamente ligados à família" (LAMARCHE, 1993, p. 15) e o agronegócio, no sentido de um modelo de agricultura empresarial, conta com o suporte da alta tecnologia para aumentar a produtividade da área cultivada a fim de exportar commodities e conferir lucratividade ao proprietário da terra. Com a posse dos recursos necessários o agricultor empresarial ganha espaço no ambiente rural, provocando a exclusão das famílias que não acompanham este modelo.

Santos (2014, p. 221) destaca que a especialização extrema por meio do uso da técnica, está vinculada às ações hegemônicas, onde o tecnicismo está relacionado à inteligência.
A materialidade do território é dada por uma gênese técnica, um conteúdo técnico e participam da condição técnica, tanto na sua realização como na sua funcionalidade. Esses sistemas técnicos atuais são formados de objetos dotados de uma especialização extrema. Isso é sobretudo válido para os objetos que participam dos sistemas hegemônicos, aqueles que são criados para responder às necessidades de realização das ações hegemônicas dentro de uma sociedade. Nunca na história do mundo houve um subsistema de técnica tão invasor. [...] É o contraste entre espaços "burros" e espaços "inteligentes". (SANTOS, 2014, p. 221)

Portanto, o agronegócio manifesta o uso exacerbado da técnica, desqualificando e excluindo as famílias que não seguem este modelo de agricultura. Na perspectiva do empresário agrícola, o espaço rural pertencente à agricultura familiar é caracterizado como atrasado e periférico.

Por fim, a territorialidade, além de incorporar uma dimensão estritamente política, também diz respeito às relações econômicas e culturais. Está ligada ao modo como as pessoas organizam no espaço o acesso aos recursos disponíveis e dão significado a determinados lugares. Assim, todo território é ao mesmo tempo funcional e simbólico, sendo que exercemos domínio sobre o espaço tanto para realizar "funções" quanto para produzir "significados" (HAESBERT, 2005).

\section{DESENVOLVIMENTO RURAL NA MICRORREGIÃO NORTE DO COREDE DO VALE DO RIO PARDO: ENFRENTAMENTOS}

Para fins de análise, neste estudo foi considerada, como objeto empírico de análise, a Microrregião Norte do COREDE do Vale do Rio Pardo/RS. Esta microrregião é constituída pelos municípios de Arroio do Tigre, Estrela Velha, Ibarama, Lagoa Bonita do Sul, Passa Sete, Segredo, Sobradinho e Tunas.

O Vale do Rio Pardo é caracterizado pela produção de tabaco e, segundo Karnopp et al. (2013, p. 9), apresenta "desigualdades internas relacionadas ao processo de formação territorial e em suas 
características socioculturais, políticas e econômicas". Os municípios que compreendem a Microrregião Norte do COREDE do Vale do Rio Pardo são os mais pobres economicamente e contam com a predominância do cultivo do tabaco por estarem localizados em uma área onde a topografia acidentada dificulta a produção de outras culturas, além disso, a produção de tabaco é tradicional na microrregião e é oferecida assistência técnica nas propriedades rurais pelas indústrias fumageiras localizadas na região Central do Vale do Rio Pardo.

No cenário nacional, a produção de tabaco é, em sua maioria, desenvolvida por agricultores familiares que adotaram esta cultura, principalmente por ela não necessitar de um longo prazo de maturação, não exigir mecanização e ainda demandar apenas uma fração de terras da propriedade. Além disso, de acordo com Franchini e Mota (2005), a fronteira agrícola brasileira do fumo encontra-se, em grande parte, nas regiões de topografia acidentada, onde a mecanização é impraticável, dificultando a difusão de outras culturas de forma abrangente. Aliado a isso, a cultura do tabaco utiliza intensiva mão de obra e é importante fonte de receita tributária, via impostos. A produção de tabaco no Brasil ainda confere a continuidade do desenvolvimento de uma agricultura familiar baseada nos princípios formatados pela "Revolução Verde". O processo de produção do tabaco - do plantio, industrialização e comercialização - é controlado pelas empresas transnacionais. Decisivamente estas corporações têm um grande impacto na configuração territorial.

Não obstante, agroindústrias familiares de alimentos se fazem presentes na Microrregião Norte do COREDE do Vale do Rio Pardo. Existem aproximadamente 51 agroindústrias familiares de alimentos na respectiva microrregião, sendo que $25 \%$ delas são formalizadas. Os agricultores familiares proprietários de agroindústrias de alimentos apresentam produtos como embutidos, farináceos, mandioca, mel, peixes, entre outros.

A Região caracteriza-se por sua estrutura fundiária baseada em propriedades rurais de pequena extensão territorial, tendo como identidade preponderante a agricultura familiar. Um número crescente dessas famílias tem buscado a agroindustrialização de seus produtos como uma forma de diversificação ou mesmo de conversão de suas fontes de renda. Esta tendência acompanha uma longa tradição colonial de produção ligada à cultura alimentar regional. Estas iniciativas resgatam diversas tradições e sabores típicos, só encontrados a partir de saberes e modos de produção específicos daqueles produtos. Alguns deles, como o käschmier (tipo de requeijão feito com leite coalhado), a linguiça aferventada, a cuca de streusel (cobertura de açúcar amanteigado) e a rapadura de amendoim, são exemplos de uma tradição que passa de pai para filho, ou de mãe para filha, e que dão sabor à vida no interior colonial.

Por um lado, a produção de tabaco que, ditada por atores globais, extrai do território os benefícios do solo e do clima, se apropriando da mais-valia gerada pela força de trabalho das famílias. Em contrapartida, a produção de alimentos através de agroindústrias de cunho familiar, se constitui no sentido de contraproposta ao processo de globalização, possuindo o significado de "recuperar sua pureza anterior e recobrir as unidades e certezas que são sentidas como tendo sido perdidas" (HALL, 2015 , p. 51), pois os produtos oferecidos pelas agroindústrias familiares (linguiça, salsichão, salame, cucas, pães caseiros, bolachas, mel, mandioca, entre outros.) expressam tradição alimentar presente nas famílias e na própria microrregião.

Segundo Hobsbawn, a simples existência de movimentos que defendem a tradição, já declara que a própria tradição foi rompida, necessitando, através da ação destes movimentos, ser recuperada ou preservada (HOBSBAWN, 2014, p. 15).

Hall (2015, p. 55) destaca que "a reafirmação das 'raízes' culturais e o retorno à ortodoxia têm sido, desde a muito, uma das mais poderosas fontes de contra identificação em muitas sociedades". Ortiz (2012, p. 105) reforça que "a cultura popular deve ser preservada porque em sua essência ela é tradição e identidade". 
Os dois fenômenos empíricos contraditórios, a produção de tabaco guiada pela hegemonia global e a produção de alimentos encabeçada por agroindústrias familiares de pequeno porte, geram tensionamentos entre $\mathrm{o}$ global e $\mathrm{o}$ regional $\mathrm{e}$ significam dois vieses de desenvolvimento particulares, porém convivem conjuntamente em um mesmo espaço geográfico e tempo histórico.

\section{A TRADIÇÃO COMO ESTRATÉGIA DE EMANCIPAÇÃO NO MEIO RURAL}

No contexto da Microrregião Norte do COREDE do Vale do Rio Pardo, a manifestação da tradição através da produção de alimentos por agroindústrias familiares pode significar um mecanismo no qual os sujeitos do território mantêm sua identidade tradicional, sem deixar que grupos imperialistas devastem as características culturais do lugar através da implementação e manutenção do cultivo do tabaco.

A cultura tradicional pode estar funcionando como uma estratégia de emancipação, especialmente para os agricultores familiares produtores de alimentos. Assim, é preciso que movimentos de caráter regional continuem se estabelecendo, com base em sua cultura tradicional, para que os agricultores familiares sejam mais autônomos frente a sua própria história.

Ortiz (2012, p. 45) afirma que nos anos 1950 - conceito de cultura é remodelado a partir dos intelectuais do Instituto Superior de estudos Brasileiros - ISEB.

Contrários a uma perspectiva antropológica que toma o culturalismo americano como modelo de referência, os intelectuais do ISEB analisam a questão cultural dentro de um quadro filosófico e sociológico. [...] Seguindo os passos da Sociologia e da Filosofia alemã, Manheim e Hegel, por exemplo, os isebianos dirão que cultura significa as objetivações do espírito humano. Mas eles insistirão no fato de que a cultura significa um vir a ser. Neste sentido eles privilegiarão a história que está por ser feita, a ação social, e não os estudos históricos; por isso, temas como projeto social, intelectuais, se revestem para eles de uma dimensão fundamental. Ao se conceber o domínio da cultura como elemento de transformação socioeconômica, o ISEB se afasta do passado intelectual brasileiro e abre perspectivas para se pensar a problemática da cultura brasileira em novos termos. (ORTIZ, 2012, p. 45-46)

A definição de cultura proveniente do ISEB propõe a utilização da cultura como recurso de transformação. A tradição como elemento de emancipação, proposta neste estudo, apresenta congruência com a definição do Instituto Superior de Estudos Brasileiros.

As tradições do lugar são especificidades únicas que devem ser providas com potência regional, garantindo força frente à homogeneização, assegurando identidade cultural e possibilitando que a região não altere sua estrutura e forma perante as exigências do capital.

O território não está dado, ele é uma construção social que se constitui a partir dos sujeitos e dos conflitos sociais. Nas palavras de Oliveira (1995, p. 11) "O campesinato deve, pois, ser entendido como classe social que ele é".

É importante ressaltar o conceito de cultura mundializada. A cultura mundializada se resume ao viés ideológico do sistema mundial, e não provoca a anulação de outras manifestações culturais, porém coabita-as, alimentando-se delas (ORTIZ, 1994, p. 26-27). Isso significa "diminuir sua complexidade para melhor apreendê-la e reproduzi-la em escala global, para tornar-Ihe universal, como por exemplo, ocorre com certas bebidas e, quase todas as marcas de cigarro" (MOREIRA, 2008, p. 33).

Nesta conjuntura é imprescindível que os agricultores familiares se apoderem de mecanismos de decisão. O simples fato de produzir alimentos tradicionais não significa emancipação, a independência advém da insubordinação frente aos atores globais. É necessária a elaboração de projetos de desenvolvimento "que priorize as oportunidades de desenvolvimento social e não se restrinja a uma perspectiva estritamente econômica e setorial" (MARQUES, 2002, p. 96). 


\section{CONSIDERAÇÕES FINAIS}

A agricultura familiar possui grande capacidade para garantir a segurança alimentar, tem fundamental importância para o desenvolvimento econômico, social e cultural e propicia a sobrevivência e a permanência de milhares de pessoas no meio rural. .

A definição de espaço rural é muito variável. Definido, muitas vezes a partir da oposição ao urbano, o rural possui características próprias. É ocupado por diferentes classes que disputam 0 próprio espaço rural e vivenciam tensões.

A preservação da cultura tradicional foi apresentada com um mecanismo de proteção à identidade cultural. No caso da Microrregião Norte do COREDE do Vale do Rio Pardo a proteção da cultura tradicional se apresentou como a tradição alimentar, podendo se transformar em um dispositivo de enfrentamento ao global. A emancipação se apresenta quando os agricultores familiares buscam projetos de desenvolvimento independentes das regras ditadas por atores globais.

Da aproximação agricultura/indústria, formouse um segmento produtivo que abrange os três setores da economia, o agronegócio, o qual adere à lógica da modernização e insere no campo, pressupostos industriais. Esse segmento tem grande representatividade econômica no mundo; porém, não pode ser tido como única forma de desenvolvimento rural que a teoria da modernização propõe, já que outros sistemas de produção são tão importantes quanto o agronegócio - agricultura familiar -, materializando, entretanto, outros resultados.

Observa-se uma importância significativa nas exportações de tabaco. O Brasil é o maior exportador mundial do produto e o seu segundo maior produtor. A cadeia possui uma estrutura centrada em oligopólio de capital multinacional que dá suporte à eficiência das relações entre os elos, refletindo-se em termos de mercado externo. O agricultor familiar, mesmo inserido no processo de forma parcial, encontra-se subordinado e distante dos lucros do capital.
Por entendermos constituir a região e o lugar frações do espaço total do planeta onde o

mundo é empiricamente percebido, o ensaio apresentado tentou corroborar a compreensão de algumas das diferentes formas de empiricização da agricultura globalizada. Partindo-se do pressuposto de que a dinâmica territorial possui duas dimensões vertical e horizontal - procurou-se evidenciar que as verticalidades são forças que prevalecem no território da região em estudo. Isto significa que o uso econômico é mais importante que o uso social do território, ou seja, os interesses econômicos externos sobrepõem-se aos interesses sociais da região. As verticalidades não consideram o interesse coletivo, não dão ênfase às interdependências e redes de solidariedade de pessoas e grupos, organizações de base local. A região se apresenta passiva e receptora da cadeia de decisões concebida a partir de fora ou de longe. Os territórios são usados somente como recursos para a satisfação de interesses exteriores a região. Conclui-se que o uso econômico e as verticalidades são mais dominantes em toda a escala local e regional.

Por meio da produção de alimentos tradicionais, o produtor rural de pequeno porte pode afastar-se da marginalização social, pois a identidade cultural presente nos produtos locais e regionais pode emancipá-los economicamente.

\section{Referências}

ABRAMOVAY, Ricardo. Paradigma do capitalismo agrário em questão. São Paulo: Hucitec, 1992.

GIDDENS, Anthony. As consequências da modernidade. São Paulo: UNESP, 1997.

GIRARDI, Eduardo Paulon. Atlas da questão agrária brasileira. Presidente prudente, 2008. Disponível em: $<$ http://www2.fct.unesp.br/nera/atlas/>. Acesso em: 30 nov. 2015.

HAESBAERT, R. Territórios alternativos. Niterói: EdUFF e São Paulo: Contexto, 2005.

HALL, Stuart. A identidade cultural na pósmodernidade. Tradução de Tomaz Tadeu da Silva e Guacira Lopes Louro. 12. ed. Rio de Janeiro: Lamparina, 2015. 
HOBSBAWN, E. J.; RANGER, T. (Org.).A invenção das tradições. Tradução de Celina Cardim Ca Valcante. 9. ed. São Paulo: Paz e Terra, 2014.

KARNOPP, E. et al. Agroindústrias familiares e a dinâmica territorial: um estudo comparativo entre a região do Vale do Rio Pardo/RS e a região do oeste catarinense/SC - Brasil. Projeto de pesquisa. Santa Cruz do Sul, 2013.

LAMARCHE, Hugues (Coord.). A agricultura familiar: comparação internacional. Campinas: Universidade de Sorocaba - Rede de Avaliação Institucional de Educação Superior (Rev. Avaliação), 1993.

MARQUES, Marta Inez Medeiros. O conceito de espaço rural em questão. Terra livre. Ano 18. n. 19. p. 95-112. Jul./dez. 2002. Disponível em: <portal.mda.gov.br/o/3467997>. Acesso em: 23 nov. 2015.

MOREIRA, Moisés Simões. A mundialização da cultura e a cidadania cosmopolita no Brasil: um diálogo possível. Revista multidisciplinar da UNIESP. n. 6. Dez. 2008. Disponível em: <http://www.uniesp.edu.br/revista/revista6/pdf/5.pdf>. Acesso em: 20 nov. 2015

OLIVEIRA, Ariovaldo Umbelino de. Modo capitalista de produção e agricultura. 4. ed. São Paulo: Ática, 1995.

ORTIZ, Renato. Cultura brasileira e identidade nacional. São Paulo: Brasiliense, 2012.

Brasiliense, 1994

Mundialização e cultura. São Paulo:

RAMOS, Pedro. Propriedade, estrutura fundiária e desenvolvimento (rural). Estudos Avançados, São Paulo, v. 15, n. 43, p.141-156, dez. 2001. Disponível em:

<http://www.scielo.br/pdf/ea/v15n43/v15n43a12.pdf>. Acesso em: 13 jul. 2015.

REIS, J. Território e sistemas produtivos locais: uma reflexão sobre as economias locais.

Revista Crítica de Ciências Sociais, Portugal, n. 25/26, 2005.

RIBEIRO, M.; MARTINS, C. A tradição já não é o que era dantes: a valorização dos produtos tradicionais face à mudança social. Economia e Sociologia, n.60. p.29-43, 1995.

SANTOS, Milton. A natureza do espaço. 4. ed. São Paulo: Edusp, 2014.

VEIGA, José Eli da. Cidades imaginárias: o Brasil é menos urbano do que se calcula. Campinas: Autores Associados, 2002.

ZUIN, L.F.S.; ZUIN, P.B. Extensão Rural: produção de alimentos tradicionais. Aparecida: Idéias \& Letras, 2008. 